\title{
'DOUTOR(A)': RELAÇÕES DE PODER E DE SOLIDARIEDADE EM UMA COMUNIDADE DE PRÁTICA JURÍDICA
} Carla Mirelle de Oliveira Matos Lisboa*
Telma Cristina de Almeida Silva Pereira**

Resumo: Com a abordagem da terceira onda da sociolinguística, o presente artigo tem como objeto de estudo as formas de tratamento direcionadas aos profissionais jurídicos em uma comunidade de prática da Defensoria Pública do Estado do Rio de Janeiro, em especial a forma 'doutor(a)'. Contamos com observação de base etnográfica e aplicação de testes de autoavaliação. Nossos resultados apontam para a existência e perpetuação do uso da forma de tratamento 'doutor(a)', principalmente para os cargos de maior hierarquia, reafirmando, assim, relações de poder entre membros com posições hierárquicas distintas e de solidariedade entre aqueles no mesmo nível hierárquico.

Palavras-chave: Doutor(a). Área jurídica. Defensoria Pública. Poder e solidariedade.

\section{INTRODUÇÃO}

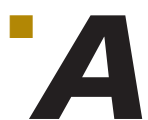

s relações entre linguagem e poder se manifestam, por vezes, de modo implícito; outras, explicitamente, como mostra o caso abaixo.

Um juiz da cidade de Niterói, no estado do Rio de Janeiro, acionou a justiça contra o condomínio em que morava, pleiteando indenizações por danos subjetivos e com o objetivo de receber tratamento formal pelos empregados do prédio, tendo em vista que é um homem público, um magistrado. Segundo o juiz, o porteiro o tratava por 'você' com o intuito de afrontá-lo. E, conforme o funcionário do edifício, o magistrado tentou exigir ser chamado de 'doutor' por conta de sua profissão de juiz de direito.

\footnotetext{
Pontifícia Universidade Católica do Rio de Janeiro (PUC-Rio) - Rio de Janeiro- RJ - Brasil. E-mail: mirellematos@gmail.com

** Universidade Federal Fluminense (UFF) - Niterói - RJ - Brasil. E-mail: tcaspereira@uol.com.br
} 
Nesse episódio, o Tribunal de Justiça do Rio de Janeiro decidiu:

Primeiramente, não se pode compelir, sob pena de pagamento de multa, alguém a chamar outrem de "SENHOR" ou "DOUTOR". Isto porque inexiste obrigatoriedade para tanto. Trata-se, entretanto, de pronome de tratamento, que demonstra maior nível de educação, não sendo esta exigivel de quem quer que seja. Ademais, a palavra que alega o autor é utilizada pelo empregado do condomínio para a ele se dirigir "VOC $\hat{E}$ ", não passa, assim, como a que pretende seja utilizada, de pronome também somente diferindo de classe [...] Aqui vai um destaque, pertinente ao cargo ocupado pelo autor. Desinfluente é que seja ele juiz de direito o que em nada interfere na forma como deve ser tratado pelos funcionários do edificio onde reside.

Tanto é que, se assim o fosse, deveria ser chamado de Excelência, o que não é exigível, a não ser quando no desempenho de suas funções, inobstante o título de seu cargo o persiga, onde quer que esteja. (BRASIL, 2006, p. 638-639).

O uso das formas de tratamento - dentre elas: 'você', 'senhor' e 'doutor' - direcionadas aos profissionais jurídicos é um assunto muito polêmico, que envolve diversas opiniões e posições acerca de qual seria o tratamento adequado a eles. Além disso, os usos das formas de tratamento podem estabelecer relações de poder ou de solidariedade entre os falantes.

Este artigo descreve o uso das formas de tratamento em uma comunidade de prática de profissionais jurídicos na Defensoria Pública do Estado do Rio de Janeiro (DPRJ), com o intuito de abordar a construção dos significados sociais atribuídos às formas de tratamento e às relações de poder e solidariedade exercidas por essas formas. O condicionamento social no uso de formas de tratamento é muito forte e nem sempre cabe ao falante optar por um tipo de tratamento, uma vez que, em muitas situações, ele é condicionado a escolher um tratamento conforme o papel social que ocupa, a quem se fala e onde se fala.

Para isso, este trabalho foi desenvolvido à luz da abordagem da terceira onda de estudos da sociolinguística variacionista, que se preocupa em analisar o valor do significado social das variáveis em comunidades de prática. Por meio dessas, é possivel captar a dimensão heterogênea da linguagem, sem homogeneizar os papéis sociais através de estratos sociais, como fazem as perspectivas de estudo que partem de comunidades de fala.

Os dados analisados aqui são parte do corpus Matos Lisboa (2015), resultante de observação de base etnográfica no núcleo de primeiro atendimento da DPRJ, Comarca de Niterói, e da aplicação de testes de autoavaliação aos membros dessa comunidade ${ }^{1}$. Esta é composta por uma defensora pública, três auxiliares jurídicas, um auxiliar jurídico, quatro estagiárias e cinco estagiários.

Pretende-se enfatizar neste texto o estilo como constituinte da identidade dos falantes e as relações de poder exercidas por meio da forma 'doutor(a)' nessa comunidade de prática. Para tanto, primeiro, será feita uma breve revisão da história da forma de tratamento 'doutor(a)'. Em seguida, há uma breve apresentação do percurso metodológico. Depois, uma discussão do estilo como consti- 
tuinte da identidade dos falantes e, por fim, serão discutidas as relações de poder e de solidariedade estabelecidas nessa comunidade de prática.

\section{HistóRIA dA FORMa de TRATAMENTo 'DOUTOR(A)’}

A forma de tratamento 'doutor(a)' é bastante usada no contexto jurídico para se dirigir aos profissionais da área, inclusive, muitas vezes, exigida por alguns deles. Consequentemente, ela é bastante usada na comunidade de prática analisada neste trabalho. Por conseguinte, apresentaremos brevemente a história dessa forma de tratamento, desde a origem latina do termo até os dias de hoje no Brasil, refletindo sobre os aspectos históricos e semânticos envolvidos. Para isso, nos fundamentaremos em Reichmann e Vasconcelos (2009). As autoras ilustram o percurso da forma 'doutor' e analisam as implicações da tradução desse título do português para o alemão, defendendo que a problemática envolve questões de diferentes culturas e vão além das descrições meramente linguísticas.

Segundo Reichmann e Vasconcelos (2009), o termo 'doutor' vem da forma latina doctor, oris ('preceptor, mestre'), cuja formação tem dois elementos: 1. o sufixo -or, típico de nomina agentis, ou seja, de nomes de profissões - ex. do latim: actor, escritor, pistor -; 2. a raiz doct-, proveniente do particípio perfeito de docere - 'instruir, ensinar' - > perf. doctum, donde vem também o adjetivo doctus -culto- e o substantivo doctrina - corpo de conhecimentos sistemáticos. O traço semântico principal do termo doctor é o conhecimento, a relação com o saber. "Assim, em latim doctor servia para designar, de maneira geral, qualquer tipo de professor, mais comumente o professor das chamadas artes liberales, isto é, as artes ou oficios dos homens livres (liberi), dos cidadãos" (REICHMANN; VASCONCELOS, 2009, p. 148).

As autoras nos mostram o percurso do termo doctor em diferentes épocas. A partir do século IV d.C., doctor recebe uma segunda e grande investidura de prestígio, com o mundo romano cristalizado, o termo passa a ter um uso eclesiástico, sendo utilizado para designar os teólogos judeus, que ensinavam a lei judaica e, consequentemente, os padres da igreja católica. "As expressões doctores ecclesiae e doctores fidei são bem recentes e o título de doctor é especialmente atribuído a São Paulo, chamado doctor mundi"(WEIJERS, 1979, p. 268, apud REICHMANN; VASCONCELOS, 2009, p. 149).

$\mathrm{Na}$ Idade Média, a relação da palavra doctor com conhecimento letrado permaneceu e se intensificou. Na Alta Idade Média, o termo doctor evocava, principalmente, a ideia de cultura letrada e competência da matéria, ainda que também estivesse relacionado com a ideia de professor; ao passo que, na Baixa Idade Média (séculos XII ao XV), recuperou seu traço de "docente", no advento das universidades medievais, que passaram a designar o professor universitário de doctores. Já no século XIII surgiram diversas leis que foram delimitando o uso do título de doctor àqueles que fizeram cursos em universidades. Os três usos mais corriqueiros do termo doutor em português eram: "o doutor médico, o doutor advogado e o doutor da igreja." (REICHMANN; VASCONCELOS, 2009, p. 150).

Por fim, convém observar que o doctoratus não era algum curso, com disciplinas a serem estudadas ou créditos a serem obtidos, mas antes um ritual, que se 
seguia à longa graduação em alguma das três faculdades superiores Medicina, Direito ou Teologia - e que tinha como função conceber publicamente $a$ licentia docendi (licença para ensinar) ao graduado. O ritual de concessão da titulação de doutor era bem pomposo e estava sujeito a determinações protocolares bastante exigentes, que variavam de universidade para universidade. (REICHMANN; VASCONCELOS, 2009, p. 151-152).

Reichmann e Vasconcelos (2009) apresentam, ainda, algumas mudanças desse quadro na Idade Moderna, pois, a partir dos séculos XIV e XV, a autoridade dos doctores começou a ser questionada de modo mais evidente. $\mathrm{O}$ valor do conhecimento deles passou a ser questionado por humanistas e místicos, além da critica ao sentimento de superioridade e arrogância que muitos doutores apresentavam. Apesar das críticas, as autoras (p. 154) destacam que o título doctor permaneceu honroso não só na Europa, mas também em colônias europeias, como no Brasil.

Assim, a tradição de se chamar advogado e médico de 'doutor' no Brasil se iniciou quando colônia, oficialmente, por meio do Decreto Imperial, de $1^{\circ}$ de agosto de 1825, que originou a Lei do Império de 11 de agosto de 1827, que "cria dois Cursos de Ciências Jurídicas e Sociais; introduz regulamento, estatuto para o curso jurídico e dispõe sobre o título de doutor para o advogado". O sistema político da época tinha uma divisão de classes pautada pela escravidão, por leis, costumes e decretos.

Embora a colonização não seja mais uma realidade brasileira atual e a situação política do Brasil seja diferente, essa tradição do uso de 'doutor(a)' permanece viva. Apesar disso, no contexto educacional, tivemos a criação da Lei de Diretrizes e Bases da Educação, lei no 9.394 de 20 de dezembro de 1996, que estabelece as diretrizes e bases da educação nacional no Brasil, inclusive da educação superior, que abrange cursos de graduação, especialização, mestrados, doutorados e pós-doutorados. Desta forma, o título de 'doutor' para advogado se torna um assunto bastante polêmico; encontram-se diversos textos na internet defendendo ou discordando de tal título para os profissionais jurídicos, inclusive escritos por advogados, que argumentam a favor ou contra tal uso. ${ }^{2}$

O Manual da Presidência da República (2002), que normatiza a redação de atos e comunicações oficiais no Brasil e possui uma seção dedicada aos pronomes de tratamento que devem ser usados em documentos oficiais, não apresenta a expressão 'doutor' como uma forma de tratamento, mas reconhece o "costume” de seu uso para bacharéis em Direito e em Medicina:

Acrescente-se que doutor não é forma de tratamento, e sim título acadêmico. Evite usá-lo indiscriminadamente. Como regra geral, empregue-o apenas em comunicações dirigidas a pessoas que tenham tal grau por terem concluído curso universitário de doutorado. É costume designar por doutor os bacharéis, especialmente os bacharéis em Direito e em Medicina. Nos demais casos, o tratamento Senhor confere a desejada formalidade às comunicações. (BRASIL, 2002 , p. 10, grifos do original).

\footnotetext{
2 Um exemplo é o artigo: "Doutor é quem faz Doutorado", escrito por um profissional jurídico (Marco Antônio Ribeiro Tura) há seis anos, que conta com 233 comentários, uns a favor e outros contra a defesa do autor. Disponível em: <http://por-leitores. jusbrasil.com.br/noticias/1682209/doutor-e-quem-faz-doutorado>.
} 
Convém lembrar que o Brasil é um país com grande desigualdade social e econômica e, como ratifica Biderman (1972/1973, p. 341): “Toda sociedade diferenciada em classes insiste em cultivar uma etiqueta que individualize a elite da massa. Em francês, em hindi, em inglês e em português há formas de tratamento que distinguem os aristocratas e a 'alta sociedade".

Quando se trata do uso da lingua, vale dizer que as formas da lingua não são determinadas por leis ou decretos, mas pelo uso e pelas convenções linguísticas propriamente ditas. A forma de tratamento 'doutor(a)' possui uma carga semântica bem maior do que a de formação acadêmica; ela carrega consigo "outros" sentidos, desde a Antiguidade. A história e a cultura de cada povo é que vai determinar esses sentidos, logo elas tendem a variar de acordo com a época e o local.

\section{Percurso metodológico}

Submetemos o projeto desta pesquisa ao Comitê de Ética e Pesquisa (CEP), através da Plataforma Brasil. Quando o CEP aprovou o projeto (CAAE: 32299014.1.0000.5289), a primeira autora deste trabalho dirigiu-se à Defensoria Pública munida do parecer do Comitê de Ética, da carta de apresentação do Programa de Pós-Graduação em Estudos de Linguagem da UFF e da declaração de pesquisa assinada por ambas as autoras para solicitar autorização da observação de base etnográfica e suas respectivas gravações. A Defensora Pública, responsável pelo setor, autorizou a pesquisa por meio da assinatura de uma "declaração de concessão de pesquisa de campo" e, ante isto, as observações de campo iniciaram-se na semana seguinte.

Foram quase dois meses (agosto e setembro de 2014) de idas à Defensoria, durante os horários de expediente do setor. Para amenizar o paradoxo do observador (LABOV, 2008), fizemos questão de ir, praticamente, todos os dias de funcionamento, nesses dois meses. Dessa maneira, com o passar dos dias, os funcionários já estavam acostumados com a presença da pesquisadora e relatavam que ela parecia ser colega de trabalho deles; desse modo, sua presença tornou-se mais comum no ambiente de pesquisa. Foi solicitada aos funcionários e assistidos, que fizeram parte da pesquisa, autorização para usar os dados de interações gravados. Essas autorizações foram concedidas por meio de assinatura do TCLE - Termo de Consentimento Livre e Esclarecido.

Durante o período de observação, diariamente, foram feitas várias anotações no diário de campo e não apenas gravações de interações entre assistidos e profissionais jurídicos. Os dados analisados neste trabalho são resultantes dessas notas de campo e gravações. Nos últimos dias de observação etnográfica, foram aplicados testes de autoavaliação ${ }^{3}$ aos profissionais jurídicos, com o intuito de verificar como eles veem a própria atuação linguística, no que se refere às formas de tratamento. A opção de deixar esse teste por último se deu com o objetivo de que as perguntas feitas não influenciassem na prática cotidiana deles durante as observações.

Cumprida essa etapa, demos continuidade por meio das transcrições ortográficas, isto é, observamos as convenções ortográficas vigentes no português e não as diferentes realizações fonéticas. Os símbolos usados para registrar as diferentes situações/ocorrências estão em Anexos (Quadro 3).

3 Mais detalhes sobre esses testes de autoavaliação podem ser vistos em: Matos Lisboa (2015) e Lisboa (2016). 


\section{TERCEIRA ONDA E O ESTILO COMO CONSTITUINTE DA IDENTIDADE DOS FALANTES}

Eckert $(2005)^{4}$ discute sobre o estudo da sociolinguística variacionista, afirmando que o foco dos estudos variacionistas, nos últimos anos, tem sido enfaticamente em dialetos regionais e étnicos, bem como na mudança linguística. Entretanto, ela propõe o estudo da variação como recurso para a construção do significado social na linguagem e, para isso, a autora mostra que os estudos da sociolinguística, com ênfase no estudo da variação, podem ser agrupados/divididos em três ondas de análise prática. Apesar de essas ondas serem uma sequência $\left(1^{\mathrm{a}}, 2^{\mathrm{a}}, 3^{\mathrm{a}}\right)$, elas não são estritamente ordenadas historicamente, nem substitutivamente; as três são partes de um todo que reflete o estudo da sociolinguística variacionista ao longo do tempo. A autora ratifica que usa o termo ondas porque cada uma representa um modo de pensar sobre variação e uma análise prática e metodológica, que cresceu a partir do resultado da anterior.

De acordo com a autora, a terceira onda tem tido um foco na variação, não só como um reflexo do lugar social, mas, sim, como um recurso para a construção do significado social; a ênfase deixa de ser nas comunidades de fala e passa a ser nas comunidades de prática. Nas palavras da autora e de McConnell-Ginet, uma comunidade de prática é:

um conjunto de pessoas agregadas em razão do engajamento mútuo em um empreendimento comum. Modos de fazer coisas, modos de falar, crenças, valores, relações de poder - em resumo, práticas - emergem durante sua atividade conjunta em torno do empreendimento. Como construto social, uma comunidade de prática é diferente da noção tradicional de comunidade, sobretudo porque é definida simultaneamente pelos seus participantes e pela prática na qual eles se engajam. Na verdade, são as práticas da comunidade e a participação diferenciada de seus membros nessas práticas que estruturam socialmente a comunidade. (ECKERT; McCONNELL-GINET, [1992] 2010, p. 102).

Eckert (2005) sintetiza a terceira onda como:

A terceira onda: a perspectiva estilística,

- Estudos etnográficos de comunidades de prática;

- Categorias locais como resultado de posições comuns;

- Variáveis como indexação de posições, atividades, características;

- Estilo como construção da persona.

De acordo com os preceitos da terceira onda da sociolinguística, o estilo é visto como uma prática, o significado social dado às ações dos falantes e o meio pelo qual os falantes combinam variáveis para criar modos distintivos de falar. Estes modos de falar são explicitamente locais na ordem social, são um modo para a produção da persona, ou seja, a produção do que o falante quer projetar,

4 Esse texto possui uma versão revisada e modificada, intitulada: Three Waves of Variation study: The Emergence of Meaning in the study of sociolinguistic Variation, de 2012. 
relacionado à multiplicidade dos papéis sociais. As pessoas constroem suas personas em comunidades de prática.

Eckert e McConnell-Ginet ([1992] 2010) afirmam que,

Durante o engajamento conjunto em tais atividades, as pessoas constroem em colaboração um sentido de si e dos outros como certos tipos de pessoas, como membros de várias comunidades com múltiplas formas de filiação, autoridade e privilégio. Em todas elas, a linguagem interage com outros sistemas simbólicos - vestimenta, adornos corporais, modos de movimento, olhar [...] (p. 97).

$\mathrm{Na}$ comunidade de prática jurídica analisada aqui, os membros também constroem suas imagens mutuamente e a linguagem deles interage com outros sistemas simbólicos, como o modo de se vestirem. Os cinco profissionais jurídicos que fazem parte dessa comunidade se vestem de maneira semelhante, todos usam roupas formais; as mulheres estão sempre de sapatos fechados, com saltos baixos ou médios, calças e blusas sociais e blazer, por conta do frio provocado pelo ar condicionado; o único profissional jurídico homem também usa sapato social, calça e camisa sociais. Do mesmo modo, os estagiários se vestem de modo formal, embora em alguns dias usem calças jeans, blusas/camisas mais despojadas, calçados abertos e nem sempre estejam de blazer. O segurança, porém, está sempre fardado. Logo a vestimenta deles é um dos sistemas simbólicos que dialoga com seus papéis sociais na comunidade.

É interessante notar, ainda, que os auxiliares jurídicos alteram a sua postura linguística dependendo dos seus interlocutores e da posição em que esses se encontram; por exemplo, na comunicação diária entre os próprios colegas que fazem parte da comunidade de prática, eles trocam tratamentos através de seus nomes próprios, de diminutivos carinhosos do nome das colegas mulheres ou do pronome de tratamento 'você'. No entanto, ao falarem sobre esses mesmos colegas com os assistidos ou ao se dirigirem aos colegas na presença do assistido, a forma de tratamento 'doutor(a)' antes dos nomes de seus nomes se torna regra.

Seguem alguns trechos de transcrições que mostram a variação entre o repertório linguístico dos auxiliares jurídicos no uso das formas de tratamento. No primeiro excerto, a auxiliar jurídica $\mathbf{2}$ usa 'doutora' ao se dirigir à colega, linha 1, para pedir o caderno de marcações. Em geral, porém, ela usa o diminutivo "Aninha" para se dirigir a essa mesma auxiliar jurídica, e recebe "Lu". Apesar disso, no excerto abaixo, ela projeta os seus papéis sociais de 'doutoras' no meio do seu atendimento de triagem com uma assistida.

(1)

1 Auxiliar jurídica 2: posso pegar aqui, doutora Ana?

2 Auxiliar jurídica 3: pode pegar ((elas estão se referindo ao caderno de marcações,

3 ambas estão fazendo atendimentos, cada uma a um assistido diferente) $)^{5}$

\footnotetext{
5 A numeração das linhas foi colocada apenas para facilitar a referência na hora de citar algo dos dados. Na transcrição original, contudo, as interações não receberam numeração por linhas.
} 
Percebe-se que os membros da comunidade usam a forma de tratamento 'doutor(a)', de modo bem marcado para falar com qualquer profissional jurídico na presença de algum assistido. Então, talvez o fato de atender aos assistidos seja suficiente para apresentar aquele que irá interagir com esses assistidos como 'doutor(a)', seja para transmitir confiança, a qual a defensora defendeu como importante para o assistido no seu teste de autoavaliação, para impor certo respeito ou para trazer à tona o papel de 'doutor(a)' do ambiente jurídico, ainda que a pessoa não seja da área. Durante a observação de base etnográfica, tivemos situações que indicaram isso, pois, depois de terminadas as triagens ou atendimentos acompanhados, ou mesmo antes dos auxiliares jurídicos iniciarem o atendimento, eles justificavam a presença da pesquisadora, apresentado-a aos assistidos como 'doutora Carla'. Isto pode ser observado no trecho transcrito abaixo. Vale dizer, porém, que em um dos atendimentos, a auxiliar jurídica $1 \mathrm{fez}$ essa apresentação ao assistido, mas como estagiária da Universidade Federal Fluminense (UFF), o que pode ser considerado uma ênfase ao fato de a pesquisadora não ser membro da área jurídica.

(2)

1 Auxiliar jurídico 1: deixe eu só trazer uma informação... essa senhora aqui... a

2 doutora Carla... ela é pesquisadora da UFF... aí ela tá fazendo a dissertação de

3 mestrado dela... a linguagem que é utilizada no meio jurídico... ((o auxiliar jurídico

4 estava explicando a minha presença na sala))

Por sua vez, podemos observar no excerto 3 usos comuns nas interações entre os membros da comunidade da Defensoria Pública, em especial, entre as mulheres. Trata-se de uma pequena conversa informal em que elas trocam agradecimentos. Note que, na linha 1, a auxiliar jurídica usa Kaká para falar com a estagiária Kátia, e na linha 4 a estagiária faz uso de 'Fá' para responder a Fátima.

(3)

1 Auxiliar jurídica 1: você tem que me ensinar isso direito Kaká ((a auxiliar jurídica se

2 refere a algo que a estagiária fez em seu celular))

3 Estagiária 4: obrigada Fá ((ela entrega uns papéis à auxiliar jurídica e 4 agradece por algo))

5 Auxiliar jurídica 1: nada ((resposta à estagiária))

A pequena interação que segue abaixo é o início de uma conversa entre o auxiliar jurídico 1 e um amigo advogado que vai tirar uma dúvida jurídica. Eles trocam formas nominais e o pronome 'você' ou o clítico 'cê', de modo muito natural e esses usos permanecem durante toda a conversa.

(4)

1 Auxiliar jurídico 1: quê que cê manda? 
2 Amigo advogado: cara... tem um caso aqui que... é um pouco complicado... vim

3 pedi uma opinião, já que você é especializado nessa área... eu deixei pra você

4 Auxiliar jurídico 1: fala sério rapaz... você é o cara

Vale ressaltar que os tipos de tratamento supracitados só acontecem em interações entre os auxiliares jurídicos que exercem as funções de secretárias e de assistentes jurídicos, com os estagiários e com algum amigo com quem eles venham a interagir. Dessa forma, esses membros trocam as mesmas formas de tratamento. Entretanto, o mesmo não ocorre quando eles se dirigem à defensora, pois, embora ela use o pronome 'você' para falar com eles, ela sempre recebe a forma de tratamento 'doutora', o que se configura na constatação de um uso categórico. Assim, o tratamento usado para as pessoas que exercem os cargos de auxiliares jurídicos para se referirem à defensora é a forma 'doutora'.

Foram encontrados, nessa comunidade de prática, dois usos categóricos da forma de tratamento 'doutor(a)' entre os membros da comunidade. O primeiro é o supracitado caso da defensora, que sempre é chamada de 'doutora' por todos, mesmo nos momentos mais informais, inclusive na comemoração de seu aniversário depois do expediente da Defensoria e, até mesmo no momento em que haveria a repetição do seu nome durante o canto de parabéns, a repetição foi: "doutora, doutora, doutora, doutora". O segundo foi o caso do segurança que sempre direciona 'doutor(a)' a todos os profissionais jurídicos, inclusive à própria defensora, seja no momento de encaminhar os assistidos ou para se dirigir a eles em outras situações.

Quanto aos estagiários, é importante ressaltar que, embora sejam graduandos e ainda não estejam formados em Direito, eles já possuem um status diferenciado na comunidade de prática, em relação ao segurança, já que, na presença dos assistidos, vez ou outra são tratados por 'doutor(a)' pelos membros da comunidade de prática e pelos próprios assistidos.

Em conversa com a defensora, ela disse que orienta os estagiários para que se apresentem aos assistidos como 'doutor(a)' seguido dos seus nomes, para que os assistidos tenham segurança no atendimento deles. Essa orientação é muito interessante para uma reflexão acerca das formas de tratamento direcionadas aos profissionais jurídicos, pois esses estagiários serão os futuros profissionais jurídicos, e, ao começarem seu estágio, já entram nesse mundo profissional, onde podem observar e vivenciar seus costumes/tradições e onde começam a ser tratados por 'doutor(a)'. Além disso, ao final do teste de autoavaliação, a defensora pública também disse que, ao passar no concurso público para a Defensoria, uma defensora mais antiga orientou em palestra aos defensores recém-aprovados que eles se apresentassem como 'doutor(a) defensor', como consta no excerto abaixo.

(5)

1 Defensora: agora quando eu passei na Defensoria... eu lembro de uma palestra que eu

2 assistia... e: uma defensora antiga falava como é que: a gente tinha que se apresentar 
3 né? vem a pessoa buscar nosso trabalho tal... iai como é que a gente se apresentava a

4 pessoa... evitar falar o nosso nome... falava assim "doutora defensora"

5 Pesquisadora: hum: interessante isso... muito interessante

6 Defensora: é... eu nunca esqueci disso... aqui é a doutora defensora... aqui eu sou a

7 defensora... entendeu? é uma forma que ela falou pra gente num: sei lá doutora Renata

8 ((seu pseudônimo))... num tenho muito problema... mas eu sempre gravei isso... as

9 vezes eu uso mais quando é aquele assistido que tá dando algum problema e tal, né?

Tais orientações nos dão um indício de que a forma de tratamento 'doutor(a)', usada para se dirigir aos profissionais que ocupam os cargos de defensores públicos, é uma tradição cultivada e transmitida entre esses profissionais jurídicos, inclusive para demarcar poder.. Tal tratamento para se dirigir à defensora se torna algo tão comum que, mesmo nos momentos mais informais compartilhados pelos membros da comunidade, como no aniversário supracitado, a defensora continua sendo tratada por "doutora". Além disso, quando ela diz, nas linhas 7-8, que não tem muito problema ser chamada pelo seu nome antecedido de doutora, não parece cogitar ser chamada apenas pelo seu nome nesse ambiente. Nota-se, pois, a importância dada ao uso dessa forma de tratamento nessa comunidade de prática.

\section{RELAÇÕes DE PODER E SOLIDARIEDAdE ENTRE OS MEMBROS DA COMUNIDADE DE PRÁTICA}

As relações de poder podem ser marcadas de várias formas e isso é muito forte no processo de interação entre as pessoas, pois os usos linguísticos podem ser convencionalizados como marcas de hierarquia e de poder. No texto The Pronouns of Power and Solidarity, Brown e Gilman (1960) mostram que determinados pronomes de tratamento revelam se as relações sociais evidenciam poder (diferenças hierárquicas/opressão) ou solidariedade, bem como a relevância da escolha desses pronomes para a distinção entre grupos. Nesse estudo, eles traçaram um quadro geral da evolução semântica dos pronomes de tratamento e convencionaram os simbolos T e V, a partir do 'tu' e do 'vos' latino, para tratar respectivamente das relações não cerimoniosas e das relações polidas, em qualquer lingua.

Segundo os autores, o poder é uma relação entre pelo menos duas pessoas, sendo que essa relação não é recíproca, é assimétrica, no sentido de que somente prescreve o uso entre superior e inferior, o que leva a escolha de determinada forma de tratamento que denote uma relação de poder numa situação comunicativa, na qual o superior usa $\mathrm{T}$ e recebe $\mathrm{V}$. Eles destacam que existem muitas bases de poder, dentre elas: força física, idade, riqueza, gênero/sexo, papel institucionalizado na igreja, na família, o status, profissão etc.

Brown e Gilman (1960) ratificam que, por muitos séculos ${ }^{6}$, o francês, o inglês, o italiano, o espanhol e o alemão mantiveram o uso dos pronomes seguindo

6 Os autores (p. 255-257) mencionam esses usos na Europa desde o século I (cartas de Pope Gregory I) até o século XVII. 
a regra não reciproca $\mathrm{T}-\mathrm{V}$ entre pessoas de poder desigual, e a regra do mútuo $\mathrm{V}$ ou $\mathrm{T}$, de acordo com a classe social, entre aqueles de poder equivalente. Não havia uma diferenciação entre iguais, mas, muito gradualmente, se desenvolveu a diferenciação para formalidade, por meio de $\mathrm{V}$, e familiaridade, por meio de $\mathrm{T}$. Essa distinção entre iguais foi chamada de solidariedade.

Esta semântica da solidariedade é recíproca, indica simetria ou intimidade entre os falantes. A solidariedade se dá por meio do tratamento recíproco entre as pessoas e entra nos pronomes europeus como um meio de diferenciar tratamento entre pessoas de poderes equivalentes. Os autores nos mostram dois sistemas bidimensionais abstratos, um em equilíbrio (ver Figura 1) e outro em conflito (ver Figura 2). No primeiro, o superior sempre recebia V, o inferior sempre recebia $\mathrm{T}$ e os que estivessem no mesmo nivel trocariam $\mathrm{T}$ para relações solidárias e V para as não solidárias. Esse sistema é representado na figura abaixo.

Figura 1 - Sistema bidimensional em equilibrio

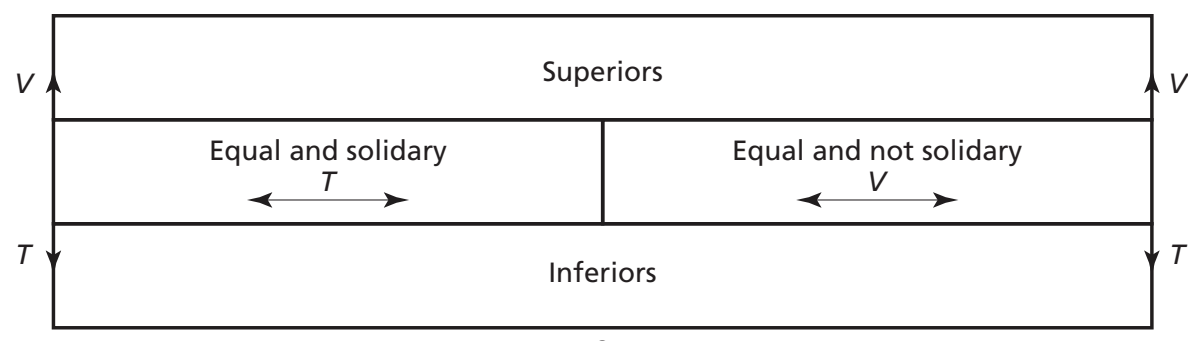

a

Fonte: Brown e Gilman (1960, p. 259).

Segundo Brown e Gilman (1960), esse sistema bidimensional parece ter permanecido equilibrado, por tempo considerável em todas as línguas. Ele, porém, veio a desestabilizar-se e entrar em conflito (Figura 2) com a extensão da dimensão da solidariedade (representada pelas linhas pontilhadas da Figura 2), que cresceu à proporção que as sociedades foram se democratizando e ampliando a mobilidade social com o avanço de ideologias igualitárias.

Figura 2 - Sistema bidimensional em conflito

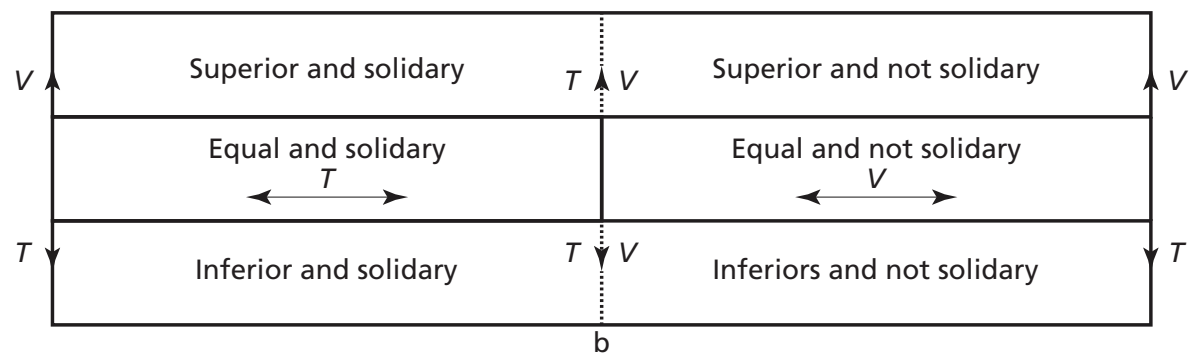

Fonte: Brown e Gilman (1960, p. 259). 
Assim, o sistema bidimensional entrou em conflito quando a dimensão da solidariedade se tornou potencialmente aplicável ao tratamento direcionado a todas as pessoas; poderes superiores podem ser solidários ou não, poderes inferiores também. Com o sistema bidimensional em equilíbrio, para que a semântica da solidariedade se estabelecesse, os interlocutores precisavam estar no mesmo nivel na hierarquia social, mas, na contemporaneidade, isso não necessariamente ocorre, já que pessoas em niveis de poder diferentes podem estabelecer relações de solidariedade ou não.

Brown e Gilman (1960) defendem que, há evidências consistentes de que algumas culturas tiveram um enfraquecimento nas relações baseadas em poder, a partir do final do século XIX, refletindo assim na evolução de algumas línguas europeias por meio da semântica dos pronomes de tratamento (covariação entre o pronome usado e a relação objetiva existente entre falante e destinatário). Consequentemente, a semântica da solidariedade ganhou supremacia no século $\mathrm{XX}$ e vem ganhando espaço na contemporaneidade.

É importante destacar, entretanto, que o sistema bidimensional em equilíbrio, como o apresentado por Brown e Gilman (1960), pode ser encontrado mesmo nos dias de hoje; de fato, a comunidade de prática jurídica analisada aqui se aproxima desse sistema em equilíbrio (ver Figura 3). Isso porque há setores que possuem os papéis sociais bem definidos e marcados pela semântica do poder e da solidariedade. Pode-se dizer que foram identificadas algumas relações de poder e de solidariedade, através do uso das formas de tratamento, entre os profissionais da Defensoria Pública.

Como exposto anteriormente, a defensora direciona 'você' para os auxiliares jurídicos que trabalham com ela e recebe, categoricamente, o tratamento 'doutora', o que se configura numa relação de poder, nos termos de Brown e Gilman (1960). Desse modo, a relação hierárquica de seu cargo é marcada pelas formas de tratamento usadas pelos membros dessa comunidade de prática.

É perceptível também que, quando os auxiliares jurídicos da comunidade de prática vão se referir ou interagir com outro(a) defensor(a) público(a) de algum outro setor ou vara, eles também usam a forma de tratamento 'doutor(a)' para se dirigir a esse(a). Um exemplo é a situação apresentada no trecho abaixo.

(6)

1 Defensora da outra sala: oi Aninha... [eu vou passar por aqui tá?]

2 Auxiliar jurídica 3: [oi doutora] ... ah fique à vontade

3 Defensora da outra sala: na volta eu vou entrar por aqui ((ela estava entrando pela

4 sala do outro setor, porque em frente à sua sala tinha muita gente))

5 Auxiliar jurídica 3: ô doutora ... meu Deus ((fazendo uso de expressão facial indicativa de 6 que ela não precisaria se justificar))

Além disso, a relação estabelecida entre o segurança e os profissionais jurídicos também é marcada por relações de poder, já que ele sempre usa 'doutor(a)' para falar com eles e recebe senhor (na forma de "seu" antecedendo seu nome: 'seu Arnaldo'/'seu Naldo'). E a maneira que o segurança encaminha o assistido ao auxiliar jurídico que irá atendê-lo (Ex.: "o senhor vai ser atendido pelo doutor Júlio") dá uma pista ao falante, que não faz parte dessa comunidade, de qual é 
a forma de tratamento considerada adequada para se dirigir ao profissional jurídico, embora, muitas vezes, ela não seja a forma usada pelos assistidos.

Em contrapartida, as formas de tratamento trocadas entre os auxiliares jurídicos com funções de assistentes jurídicos e secretárias (intermediários na cadeia hierárquica) são marcadas por relações de solidariedade, pois, como já foi dito, os quatro auxiliares jurídicos, que estão no mesmo nível hierárquico, trocavam 'você' e tratamentos pelos seus nomes próprios ou por diminutivos carinhosos dos mesmos.

No que se refere ao tratamento empregado entre os estagiários e os outros membros da comunidade de prática, há tanto relações de poder quanto de solidariedade, a depender de com quem eles estejam interagindo. As relações de poder se manifestam quando eles estão interagindo com a defensora pública e as de solidariedade entre eles ou com os auxiliares jurídicos. Por sua vez, com o segurança não há uma estabilidade nessa troca, pois ele usa tanto 'você' no cotidiano quanto 'doutor(a)' para se dirigir aos estagiários na frente de alguns assistidos, talvez por eles serem muito jovens e ainda não serem profissionais jurídicos.

As relações estabelecidas na troca das formas de tratamento podem ser resumidas na figura que segue.

Figura 3 - Estrutura de poder e de solidariedade da comunidade de prática da DPRJ

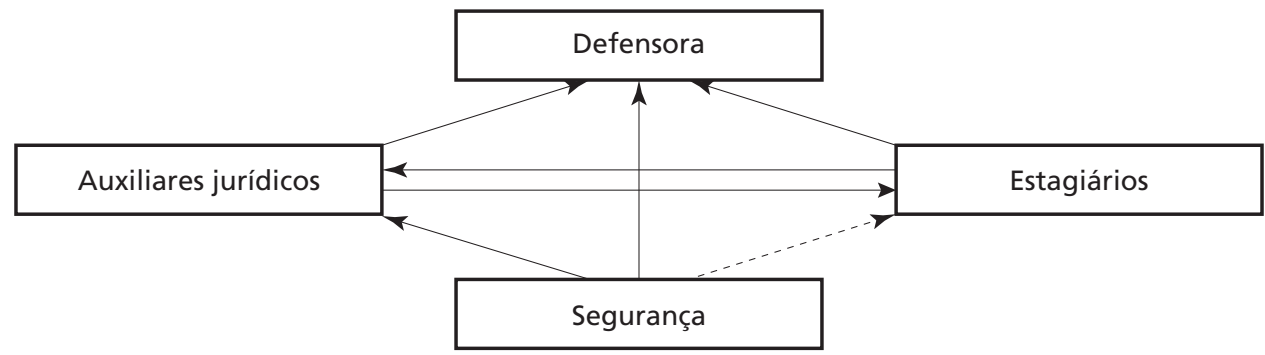

Essa figura representa uma espécie de estrutura semiestabilizada das relações de poder e solidariedade no sistema bidimensional, visto que as formas de tratamento trocadas pela defensora são marcadas pela dimensão de poder, presente também entre o segurança e os demais membros da comunidade que estão numa escala hierárquica superior, enquanto as formas trocadas entre os profissionais de poderes equivalentes manifestam a dimensão da solidariedade. Isto é, a defensora sempre direciona 'você' aos membros da comunidade de prática e das outras camadas sempre emana 'doutora' para ela, bem como os auxiliares jurídicos e os estagiários trocam a mesma forma de tratamento 'você'/'formas nominais', enquanto os auxiliares jurídicos sempre recebem 'doutor(a)' do segurança, que é tratado por 'você' ou 'senhor'/'seu'. Todavia, se fez necessário o uso do prefixo "semi” (em semiestabilizado), pois os estagiários não têm uma posição hierárquica muito bem marcada em relação aos outros profissionais. Além disso, há momentos em que eles recebem 'você' do segurança, uma vez que, eles têm bem menos idade que o segurança e ainda são estu- 
dantes jurídicos em formação, por isso se usou a linha pontilhada entre o segurança e os estagiários.

Nesse sistema da comunidade jurídica analisada, a semântica da solidariedade se manifesta entre pessoas com igual poder e a dimensão do poder guia o tratamento entre pessoas com poderes diferentes. Percebe-se, pois, que o papel social/cargo de cada membro na instituição é fundamental para a escolha da forma de tratamento no contexto dessa comunidade de prática.

\section{CONSIDERAÇÕES FINAIS}

Uma vez que o contexto jurídico parece ter os papéis sociais e hierárquicos bem marcados, inclusive pelas formas de tratamento, este artigo traz uma contribuição para o entendimento da estrutura na comunidade de prática jurídica. Fica notório que a forma de tratamento 'doutor(a)' exerce um papel diferenciado na comunidade. Mostramos que há uma estrutura semiestabilizada das relações de poder e solidariedade no uso das formas de tratamento. Assim, o acompanhamento etnográfico na DPRJ nos mostra que as escolhas das formas de tratamento entre os membros dessa comunidade de prática já estão preestabelecidas por convenção de uso. Em suma, este estudo do uso das formas de tratamento entre os membros da comunidade de prática mostrou-se muito relevante, pois auxiliou na classificação das relações hierárquicas dos cargos e do papel social de cada profissional presente.

\section{ANEXOS}

Quadro 1 - Distribuição e dados sociais dos funcionários da Defensoria Pública, que são membros da comunidade de prática

\begin{tabular}{|l|l|l|l|l|}
\hline Sexo/ gênero & $\begin{array}{l}\text { Cargo/função } \\
\text { que exerce }\end{array}$ & Idade & $\begin{array}{l}\text { Participante } \\
\text { (pseudônimos) }\end{array}$ & Formação \\
\hline Feminino & Defensora & 44 anos & $\begin{array}{l}\text { Defensora } \\
\text { (Renata) }\end{array}$ & $\begin{array}{l}\text { Bacharel em } \\
\text { Direito }\end{array}$ \\
\cline { 2 - 6 } & $\begin{array}{l}\text { Assistente } \\
\text { jurídico }\end{array}$ & 56 anos & $\begin{array}{l}\text { Auxiliar jurídica 1 } \\
\text { (Fátima) }\end{array}$ & $\begin{array}{l}\text { Bacharel em } \\
\text { Direito }\end{array}$ \\
\cline { 2 - 6 } & Secretária & 40 anos & $\begin{array}{l}\text { Auxiliar jurídica 2 } \\
\text { (Luciana) }\end{array}$ & $\begin{array}{l}\text { Bacharel em } \\
\text { Direito }\end{array}$ \\
\cline { 2 - 5 } & Secretária & 44 anos & $\begin{array}{l}\text { Auxiliar jurídica 3 } \\
\text { (Ana) }\end{array}$ & $\begin{array}{l}\text { Bacharel em } \\
\text { Direito }\end{array}$ \\
\hline Masculino & $\begin{array}{l}\text { Assistente } \\
\text { jurídico }\end{array}$ & 32 anos & $\begin{array}{l}\text { Auxiliar jurídico 1 } \\
\text { (Júlio) }\end{array}$ & $\begin{array}{l}\text { Bacharel em } \\
\text { Direito }\end{array}$ \\
\cline { 2 - 5 } & Segurança & 53 anos & $\begin{array}{l}\text { Segurança } \\
\text { (Arnaldo) }\end{array}$ & $\begin{array}{l}\text { Ensino } \\
\text { Fundamental } \\
\text { incompleto }\end{array}$ \\
\hline
\end{tabular}


Quadro 2 - Distribuição e dados sociais dos estagiários que são membros da comunidade de prática e compõem a amostra

\begin{tabular}{|c|c|c|c|}
\hline Sexo/gênero & Idade & $\begin{array}{l}\text { Periodo do curso de } \\
\text { Direito }\end{array}$ & $\begin{array}{l}\text { Estagiário n. } \\
\text { (pseudônimos) }\end{array}$ \\
\hline \multirow[t]{4}{*}{ Feminino } & 20 anos & $4^{\circ}$ período & $\begin{array}{l}\text { Estagiária } 1 \\
\text { Lúcia }\end{array}$ \\
\hline & 20 anos & $4^{\circ}$ período & $\begin{array}{l}\text { Estagiária } 2 \\
\text { Amanda }\end{array}$ \\
\hline & 20 anos & $6^{\circ}$ período & $\begin{array}{l}\text { Estagiária } 3 \\
\text { Camila }\end{array}$ \\
\hline & 20 anos & $4^{\circ}$ período & $\begin{array}{l}\text { Estagiária } 4 \\
\text { Kátia }\end{array}$ \\
\hline \multirow[t]{5}{*}{ Masculino } & 19 anos & $3^{\circ}$ período & $\begin{array}{l}\text { Estagiário } 1 \\
\text { Rafael }\end{array}$ \\
\hline & 22 anos & $5^{\circ}$ período & $\begin{array}{l}\text { Estagiário } 2 \\
\text { Lucas }\end{array}$ \\
\hline & 20 anos & $5^{\circ}$ período & $\begin{array}{l}\text { Estagiário } 3 \\
\text { Miguel }\end{array}$ \\
\hline & 20 anos & $5^{\circ}$ período & $\begin{array}{l}\text { Estagiário } 4 \\
\text { Douglas }\end{array}$ \\
\hline & 21 anos & $8^{\circ}$ período & $\begin{array}{l}\text { Estagiário } 5 \\
\text { Mateus }\end{array}$ \\
\hline
\end{tabular}

Quadro 3 - Símbolos usados para as transcrições das interações

\begin{tabular}{|l|l|}
\hline Ocorrências & Símbolos \\
\hline Incompreensão de palavras ou segmentos. & $($ ) \\
\hline Hipótese do que se ouviu. & (hipótese) \\
\hline Prolongamento de vogal ou consoante. & $:::$ \\
\hline Interrogação. & $?$ \\
\hline Exclamação. & $!$ \\
\hline Qualquer pausa. & $\ldots$ \\
\hline Pausa longa. & $::: .$. \\
\hline Comentários descritivos do transcritor. & $($ (comentário)) \\
\hline Superposição, simultaneidade de vozes. & [ ] \\
\hline Citações literais ou leituras de textos, durante a gravação. & “ ” \\
\hline
\end{tabular}

Fonte: adaptado de Preti (2005, p.19-20). 


\title{
"Doctor": Power Relations And Solidarity In A Community Of Practice
}

\begin{abstract}
Through the third wave of sociolinguistics, this paper has as object of study the power relations in language, through the forms of treatment directed at legal professionals in a Public Defender's Office community of practice in the State of Rio de Janeiro. We did an ethnographic observation and an application of self-assessment tests. Through the results, we note the existence and perpetuation of the use of the form of treatment 'doctor' including members of the community, particularly to the ones in higher hierarchical positions. Thus, the prevailing power relations is seen among the members who have different hierarchical positions and of solidarity among those who are at the same level of the hierarchy.
\end{abstract}

Keywords: Doctor. Juridical area. Public defense. Power and solidarity.

\section{REFERÊNCIAS}

BIDERMAN, M. T. Formas de tratamento e estruturas sociais. Alfa, n.18/19, p. 339-381, 1972/1973.

BRASIL. Lei do Império, de 11 de agosto de 1827. Disponivel em:<http://www. planalto.gov.br/ccivil_03/revista/Rev_63/Lei_1827.htm> Acesso em: 27 jun. 2011.

BRASIL. Presidência da República Casa Civil. Manual da Presidência da República, 2002. Disponivel em: <http://www.planalto.gov.br/ccivil_03/manual/ manual.htm> Acesso em: 14 nov. 2014.

BRASIL. Lei $\mathrm{n}^{\circ}$ 9.394, de 20 de dezembro de 1996. Disponivel em: <http:// www.planalto.gov.br/ccivil_03/leis/L9394.htm>. Acesso em: 10 abr. 2016.

BRASIL. Tribunal de justiça do Estado do Rio de Janeiro (nona câmara cível). Apelação civel $n^{\circ}$ 35610/2005. Apelente: Antônio Marreiros da Silva Melo Neto. Apelados: condomínio Edifício Luiza Village e outro. Relator: Renato Simoni. Rio de Janeiro, 24 de janeiro de 2006.

BROWN, R.; GILMAN, A. The pronouns of power and solidarity. In: SEBEOK, T. A.(ed.) Christina Style in language: MIT Press, p. 252-281, 1960.

ECKERT, P. Variation, convention and social meaning. Paper Presented at the Annual Meeting of the Linguistic Society of America. Oakland, 2005.

ECKERT, P.; McCONNEL-GINET S. Comunidades de prática: lugar onde co-habitam linguagem, gênero e poder (1992) In: OSTERMANN, A. C.; FONTANA, B. (org.). Linguagem, gênero, sexualidade: clássicos traduzidos. São Paulo: Parábola. p. 93-108, 2010.

LISBOA, C. M. M. Efeitos de sexo/gênero na escolha de formas de tratamento: análise em uma comunidade de prática jurídica de Niterói, p. 267-290. In: FREITAG, R. M. Ko.; SEVERO, C. G. (Org). Mulheres, linguagem e poder - Estudos de Gênero na Sociolinguística Brasileira. São Paulo: Blucher, 2015. 
MATOS LISBOA, C. M. de O. Doutor e outras formas de tratamento direcionadas aos profissionais jurídicos: análise de uma comunidade de prática à luz da terceira onda da sociolinguística. 2015. 129 f. Dissertação (Mestrado em Estudos de linguagem)-Universidade Federal Fluminense, Niterói, 2015.

REICHMANN, T.; VASCONCELOS, B. A. "Seu Dotô"/Herr Doktor: aspectos históricos e linguísticos do tratamento de Doutor e as consequências para a tradução. Pendaemonium germanicum. 13, p.146-170, 2009.

Recebido em 21-07-2016. Aprovado em 26-07-2016. 